\title{
TEKNIK PEMBUATAN KUCUR UNTUK UMPAN PANCING DI SUNGAI MUSI, SUMATERA SELATAN
}

\author{
Burnawi*) \\ *Teknisi Litkayasa pada Balai Riset Perikanan Perairan Umum, Palembang
}

Teregristasi I tgl. 23/11/2005; Disetujui terbit tgl. 23/11/2005

\section{PENDAHULUAN}

Sungai Musi merupakan sungai terpanjang dan terbesar di Propinsi Sumatera Selatan terdiri dari 9 sungai yaitu: Sungai Musi, Sungai Kikim, Sungai Kelinggi, Sungai Lakitan, Sungai Rawas, Sungai Batanghari Leko, Sungai Lematang, Sungai Ogan, dan Sungai Komering.

Kegiatan perikanan yang dominan di Sungai Musi ialah penangkapan ikan dengan berbagai alat tangkap, antara lain: pancing, rawai, jala, jaring insang, bubu, tuguk, empang, dan lain-lain. Diantara alat-alat tersebut yang cukup unik adalah penangkapan ikan memakai pancing umpan "kucur".

Kucur adalah umpan pancing yang terbuat dari: lemak sapi, ikan, jengkol, bawang putih, kemiri, pala, minyak goreng, kapas, dan telur itik yang melalui proses dimasak dan difermentasi. Umpan ini mempunyai aroma busuk yang khas dan menarik ikan untuk memakannya, terutama jenis-jenis ikan buas. Kelompok ikan berpatil (catfish) seperti ikan: baung (Mytus nemurus), patin (Pangasius spp), dan berengit (Mytus nigriceps) menyukai umpan "kucur" yang tenggelam di dasar sungai.

Tujuan penulisan makalah ini adalah menguraikan teknik pembuatan kucur untuk umpan pancing, sebagai informasi bagi nelayan dan kalangan hobis pemancing di Sungai Musi, Sumatera Selatan.

\section{POKOK BAHASAN}

Teknik membuat kucur untuk umpan pancing ditulis berdasarkan hasil wawancara langsung dengan nelayan yang membuat kucur. Dalam proses pembuatan kucur ini ada beberapa pokok bahasan yang menyangkut tentang: alat, bahan, dan cara kerja.

\section{Alat}

Alat yang digunakan untuk membuat kucur adalah sebagai berikut: kompor, kuali, pisau dapur, baskom plastik, penggerus (blender, cowet, lumpang batu), kaleng bekas biskuit, kaleng bekas susu, kantong plastik, talenan, mangkok, sendok, sendok masak (cooking spoon), dan timbangan lihat Tabel 1.

Tabel 1. Alat pembuatan kucur

\begin{tabular}{clc}
\hline No. & Alat & Jumlah \\
\hline 1. & Kompor & 1 buah \\
2. & Kuali & 1 buah \\
3. & Pisau dapur & 1 buah \\
4. & Baskom plastik & 1 buah \\
5. & Penggerus (Blender, lumpang batu) & 1 buah \\
6. & Kaleng bekas biskuit Volume $5 \mathrm{I}$ & 1 buah \\
7. & Kaleng bekas susu volume $400 \mathrm{ml}$ & 1 buah \\
8. & Kantong plastik ukuran $30 \times 20 \mathrm{~cm}$ & 50 lembar \\
9. & Talenan & 1 buah \\
10. & Mangkok & 1 buah \\
11. & Sendok & 1 buah \\
12. & Sendok masak & 1 buah \\
13. & Timbangan ketelitian $10 \mathrm{~g}$ & 1 buah \\
\hline
\end{tabular}




\section{Bahan}

Pembuatan kucur ini terdiri dari beberapa macam bahan yaitu: ikan berengit, lemak sapi, kapas, jengkol, bawang putih, kemiri, pala, minyak goreng, dan telur itik. Ikan berengit adalah bahan baku utama untuk pembuatan kucur yang berfungsi untuk memberikan aroma busuk yang khas dan mempunyai daya tarik tersendiri bagi ikan untuk memakan umpan kucur tersebut. Bila di suatu daerah tidak ada ikan berengit maka dapat diganti dengan jenis ikan lainnya.

Adapun komposisi bahan pembuatan kucur (ada di Tabel 2).

Tabel 2. Bahan dan komposisi pembuatan kucur

$\begin{array}{lll}\text { No. B a h a n } & \text { Jumlah (gram ) } & \text { Jumlah (\%) }\end{array}$

\begin{tabular}{llcc}
\hline 1. & Ikan berengit & 3.000 & 67,18 \\
2. & Lemak(gajih) sapi & 500 & 11.19 \\
3. & Kapas & 300 & 6,71 \\
4. & Jengkol & 100 & 2,23 \\
5. & Bawang putih & 100 & 2,23 \\
6. & Kemiri & 100 & 2,23 \\
7. & Pala & 100 & 2,23 \\
8. & Minyak Goreng & 100 & 2,23 \\
9. & Telur itik & 65 (1 buah ) & 1,45 \\
\hline & Jumlah & 4.365 & 100,00 \\
\hline
\end{tabular}

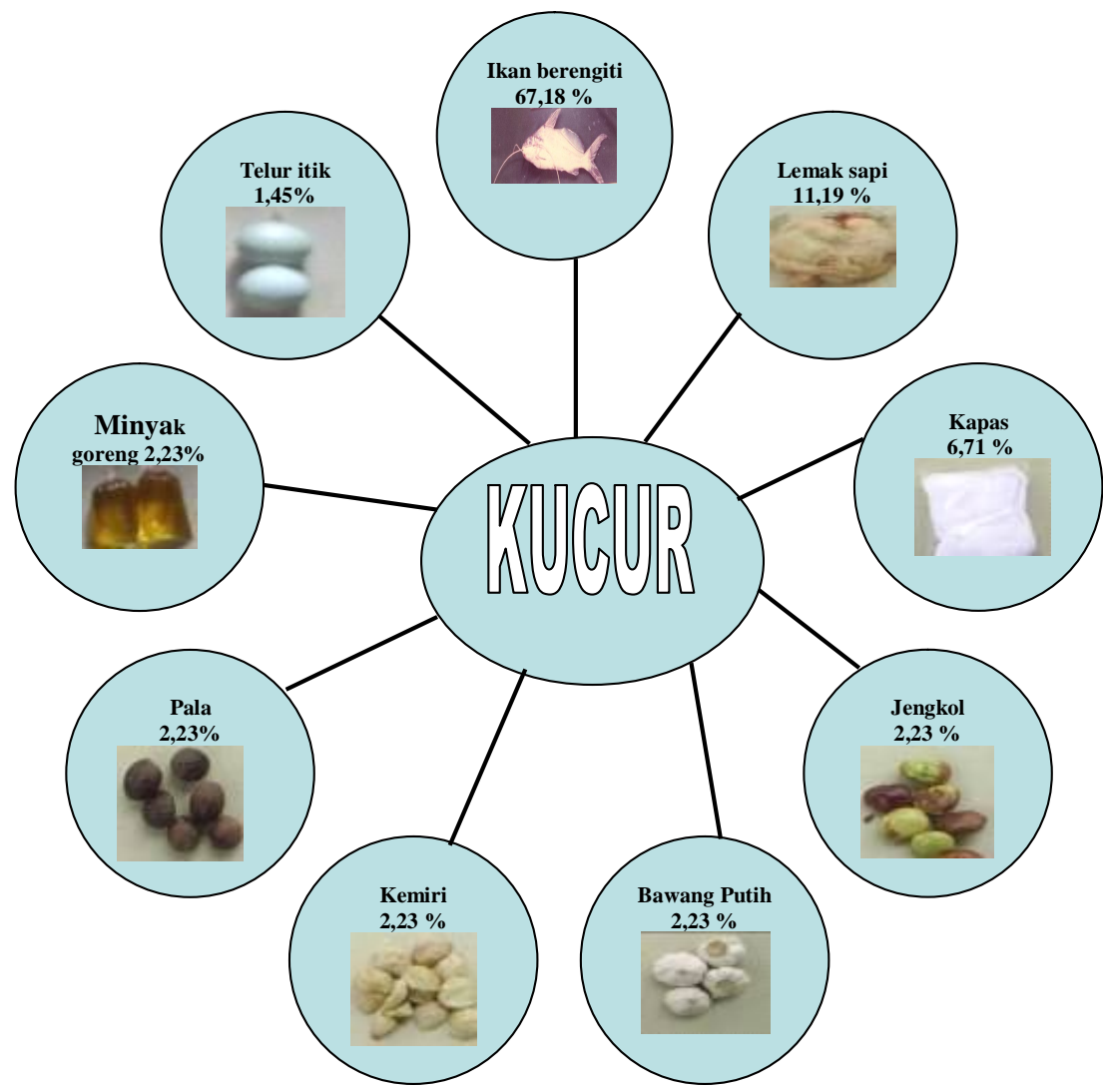

Gambar 1. Diagram foto bahan untuk membuat kucur. 


\section{CARA KERJA}

\section{Persiapan}

Semua bahan disiapkan untuk ditimbang sesuai dengan komposisi tersebut di atas dan bahan dihaluskan dengan cara digerus atau ditumbuk memakai alat blender, cowet atau lumpang batu yaitu: ikan berengit, bawang putih, jengkol, dan kemiri. Kemudian lemak sapi dicincang atau diiris memakai pisau sehingga menjadi potongan-potongan berukuran kurang lebih $5 \mathrm{~cm}$ dan selanjutnya telur itik dikocok hingga rata selama 1 menit.

\section{Proses memasak}

- Panaskan minyak goreng di dalam kuali, setelah itu masukan bawang putih, kemiri, pala, sehingga beraroma, lalu jengkol sambil diaduk hingga rata dan kemudian masukkan ikan berengit yang telah dihaluskan sambil diaduk hingga rata.

- Masukkan lemak sapi yang telah diiris kecil-kecil ke dalam tumisan sambil diaduk hingga lemak tersebut mencair menjadi minyak.
- Lemak sapi berfungsi menyatukan, menempelkan, dan mengikat bahan-bahan kucur hingga homogen.

- Setelah itu masukkan telur itik yang telah dikocok dan diaduk selama 1 menit hingga tercampur rata.

- Setelah selesai proses memasak bahan-bahan tersebut dituangkan ke dalam baskom, lalu dimasukkan kapas sedikit demi sedikit sambil diaduk hingga seluruh kapas tersebut bercampur dengan bahan yang telah dimasak.

- Kapas berfungsi sebagai substrat tempat menempelkannya bahan-bahan baku kucur yang bersifat encer dan lunak.

- Bila bahan kucur sudah dingin lalu dimasukkan ke dalam wadah (kaleng bekas biskuit volume $5 \mathrm{~kg}$ ) dan ditutup rapat kedap udara.

- Setelah 2 minggu akan terjadi proses fermentasi, lalu kucur dikeluarkan dari dalam kaleng biskuit dan dikemas dalam kaleng bekas susu yang dibungkus dengan kantong plastik, pembungkusan ini bertujuan agar bau busuk tidak keluar dari kaleng dan siap untuk dijadikan umpan pancing (Gambar 2).

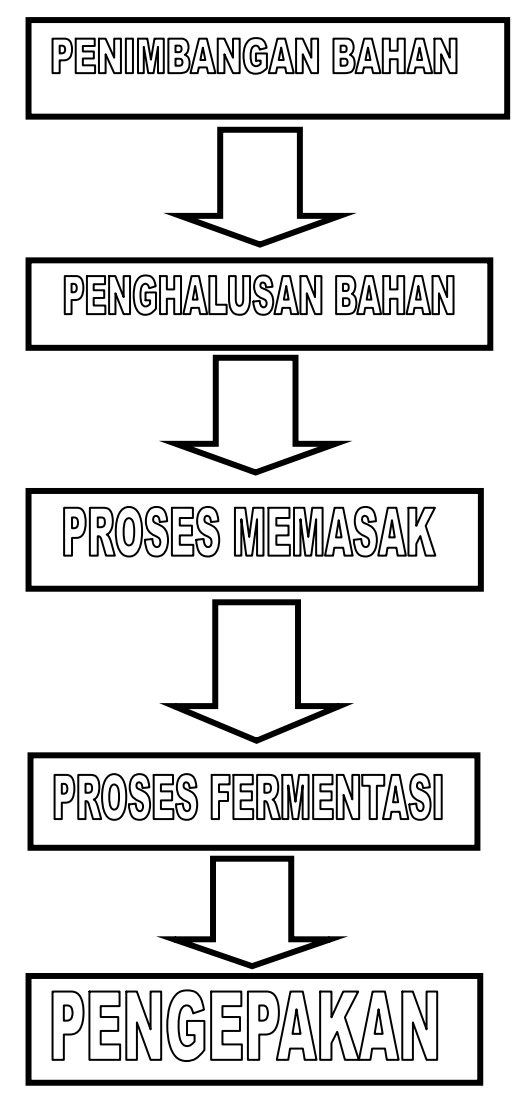

Gambar 2. Diagram proses pembuatan kucur. 


\section{Hasil pembuatan kucur}

Dari komposisi bahan kucur tersebut di atas akan dihasilkan kucur seberat $4 \mathrm{~kg}$, atau bila dibungkus dengan kemasan yang lebih kecil maka akan dihasilkan sebanyak 40 kemasan (kaleng bekas susu) dengan berat $\pm 100 \mathrm{~g} /$ kemasan .

\section{KESIMPULAN}

1. Kucur adalah umpan buatan yang banyak dipakai oleh masyarakat di Sungai Musi.
2. Teknik pembuatan kucur dapat di jadikan acuan oleh nelayan dan para kalangan hobis memancing ikan khususnya nelayan Sumatera Selatan. Bahan baku pembuatan kucur terutama jenis ikan beringit dapat diganti dengan jenis ikan lainnya.

\section{UCAPAN TERIMA KASIH}

Dalam kesempatan ini penulis menyampaikan ucapan terima kasih sebesar-besarnya kepada Bapak Rosik sebagai nara sumber. 